\title{
Creating Innovative Frameworks to Spur Cultural Change at the NASA Armstrong Flight Research Center
}

\author{
Aamod Samuel \\ NASA Armstrong Flight Research Center \\ Edwards, CA, 93523 \\ aamod.g.samuel@nasa.gov \\ 661-276-2155 \\ Joel Lozano \\ NASA Ames Research Center \\ Moffett, CA 94035 \\ joel.b.lozano@nasa.gov \\ 650-604-2849
}

\author{
Olivia Carte \\ NASA Armstrong Flight Research Center \\ Edwards, CA, 93523 \\ olivia.j.carte-1@nasa.gov \\ 661-276-2247 \\ Troy Robillos \\ NASA Armstrong Flight Research Center \\ Edwards, CA, 93523 \\ troy.a.robillos@nasa.gov \\ 661-276-5511
}

\begin{abstract}
Changing the culture of an organization is a monumental task that often takes years and has no set formula. Steps can be taken, however, to spur cultural change by creating spaces and infrastructure to serve as the initial driving force. An innovation space and a bicycle sharing (bike share) program were implemented at the National Aeronautics and Space Administration (NASA) Armstrong Flight Research Center (AFRC) (Edwards, California) with a vision toward connecting Center personnel, fostering collaboration and innovation, retaining newer employees, promoting flexibility, and improving the culture and workplace atmosphere. This paper discusses the steps taken, challenges faced, novel culturechange-focused design elements, lessons learned, acquired

selection based on lessons learned, creating bike stations and signage, implementing bike share rules, and building a volunteer maintenance infrastructure. A novel user-reporting feedback system at each bike station is a low-impact method of capturing usage metrics. Due to the nature of the work conducted at AFRC, the bike share program and feedback system were negotiated and vetted through various organizations including legal, safety, and operations. The innovation space and the bike share program together are an effective initial framework for innovation and collaboration. Culture change takes time, but the innovation space and the bike share program are already showing signs of making a positive impact on the AFRC workforce.
\end{abstract} metrics, and how these initiated cultural change at AFRC. For both the innovation space and the bike share program, funding was negotiated and provided through the NASA Convergent Aeronautics Solutions (CAS) project, which was seeking to improve the innovation and collaboration capabilities at each of the four NASA aeronautics Centers. Key stakeholders across AFRC from upper management, facilities, safety, engineering, and procurement were identified early in the process and were consulted and included throughout execution to ensure that any encountered roadblocks could be easily navigated. Research was then conducted by attending conferences and visiting culture-changing organizations both inside and outside United States Government agencies. Distilling the research, identifying available space, and deciding on specific design elements for the space was conducted by a subset of individuals of diverse backgrounds to enable quick, effective decision-making. Decisions were made with the intent to increase usage and diversity of users of the space; care was taken to ensure a wellcrafted atmosphere that would foster the desired culture change. The allocated physical space required major structural modifications, new furniture, and new capabilities that would bring people in. Decisions and desires underwent a rapid reiterative process in order to stay within budget and short deadlines, while holding firm to what was seen as fundamental elements of an innovation space. The framework for cultural change being established, the more difficult task began: incubating the desired culture.

Intentional workday use of the innovation space was encouraged, and organized events coordinated in order to truly foster culture change. Such incubation supports the organic spread of culture change to all areas of AFRC. This framework was complemented and expanded by the implementation of the bike share program. Steps for implementation included bike U.S. Government work not protected by U.S. copyright.

\section{TABLE OF CONTENTS}

1. INTRODUCTION ...............................................................1

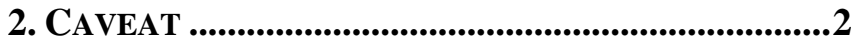

3. BACKGROUND ..........................................................2

4. Current State .........................................................3

5. EXISTING Positive CULTURE ................................3

6. DESIGN: INNOVATION/COLLABORATION ROOM..4

7. DESIGN: BIKE SHARE PROGRAM ..............................7

8. RESULTS: INNOVATION/COLLABORATION

SPACE ..........................................................................8

9. RESUlts: BIKE SHARE PROGRAM ......................10

10. CONCLUSION ....................................................11

ACKNOWLEDGEMENTS .....................................12

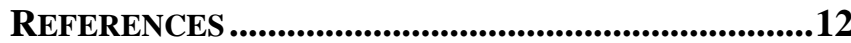

ADDITIONAL READING .............................................12

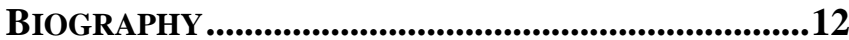

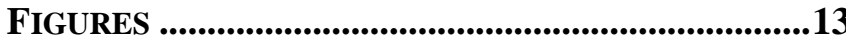

\section{INTRODUCTION}

Promoting and increasing innovation is crucial for any research and test organization, and the National Aeronautics and Space Administration (NASA) is no exception. NASA's future success and growth depend on the ability to adapt and stay on the cutting edge of technologies and processes. A 
commitment must be made to continuous improvement in innovation culture and work environments. At the NASA Armstrong Flight Research Center (AFRC) (Edwards, California) several opportunities were seen to improve the culture in order to promote retention, innovation, and collaboration, and to close the communication and collaboration gap among employees and workgroups across the Center. Many United States Government agencies, as well as the commercial sector, are moving toward centralized spaces where employees can come together to brainstorm, encourage each other's creativity, and make connections with others; not just professionally, but also on a personal level. When employees are allowed the flexibility to connect with others not only in their local working group, but across their Center and even across NASA, positive cultural change is fostered. Potential benefits include improved work efficiency and effectiveness, overall employee engagement, and an atmosphere that fosters creativity and is exciting for people to work in. When a large part of the workforce is nearing retirement age, and another significant portion is just beginning their career, it is critical to find a way to enable lasting bonds between employees of all levels. These bonds between individuals across AFRC can lead to effective work, overall improvement in wellness, and effective knowledge sharing. This paper focuses on how the authors utilized support and resources and teamed together to create an innovation space in which to foster a culture of connection, collaboration, and innovation; our vision, design, and execution of building the space; the design and execution of another culture-fostering framework; lessons learned from the project; and our future goals.

At the inception of this project, the Center Director at AFRC, David McBride, already had a vision to create a space that would serve as a combination break room and collaboration room. A space that was mostly unused was selected for this purpose and for use by the Research Operations (RO) branch. The RO branch intended to use the space to store the circulating collection of the research library and house the Library Technician. The NASA Foundations of Influence, Relationships, Success, and Teamwork (FIRST) AFRC team interfaced with personnel from the RO branch and kept them involved throughout the process. The FIRST team established its own core vision that was in line with the Center Director's vision and that of RO branch personnel, and began creating a design that would both benefit the Center and create a framework for cultural change toward a more connected, engaged, and innovative workforce.

\section{Caveat}

This paper, written by members of the FIRST team, is presented for the purpose of sharing the experience of creating innovative frameworks to foster culture change within an organization. The information presented was gleaned through the process and observation of the results. The frameworks have been in place slightly more than one year; success or failure cannot yet be fully analyzed. Furthermore, some of the change in culture is not easily quantified. Data are presented for some notional trends, but those data are not meant to represent definitive conclusions. The authors urge the reader to gain some lessons learned through our process of executing this project and gain ideas on how one might create these frameworks and promote culture change in an organization.

\section{BACKGROUND}

The idealist might propose that a culture of innovation does not come about by way of budgets or investments toward it; many are hesitant to make financial investments in programs that do not directly contribute to the explicit mission of an organization. The innovation space project team thus was willing to consider utilizing a very small budget to use for activities and infrastructure upgrades to enable an innovative and connected culture. The original plan was to find excess furniture, an available space, and some time to create events. (The authors believe it is possible to change culture in this way, but the pace of change will be much slower and a greater time commitment will be needed). The team was not aware that President Obama's "A Strategy for American Innovation" [Ref. 1] was not just a paper that mentioned NASA 12 distinct times in the context of innovation, CubeSats, commercial space, and a myriad of other things, but that Agency leaders such as NASA Administrator Charles Bolden were already funding an "augmentation" of budgets for the sole purpose of improving the innovative culture of NASA. For the team, this was in the arena of Convergent Aeronautics solutions. As an aeronautics research Center, AFRC forged its original culture deep in the heart of its flight research mission. Chuck Yeager, after breaking the sound barrier in the Bell X-1, landed on the same airfield that AFRC now uses for aeronautics research platforms. The AFRC is one of four NASA Centers with programs that are distinctly for aeronautics research: along with AFRC, the Langley Research Center (Hampton, Virginia), the Glenn Research Center (Cleveland, Ohio), and the Ames Research Center (Moffett Field, California) each have aeronautics research programs that are governed at the program level by the Aeronautics Research Mission Directorate (ARMD) at NASA Headquarters (HQ) in Washington, D.C. Convergent Aeronautics Solutions (CAS), while an Aeronautics program, operates on a different model than traditional NASA programs. The CAS program encourages short-duration activities in order to establish early-stage concepts and, by iterating successful ideas, enables larger ideas to emerge and then be executed on a larger scale. The CAS program received a portion of Mr. Bolden's budget "augmentation:" approximately $\$ 4$ million was provided, to specifically "identify, assess, and adapt alternative methods and tools to support an innovative culture and build an innovative workforce able to respond to global trends including accelerating pace of technological change, ready access to technical information, advances in technologies outside of aeronautics, and increasing complexity of society." [Ref. 2] (Emphasis added.)

Starr Ginn, CAS champion and program coordinator for AFRC, recognizing an opportunity to develop younger employees, delegated much of the planning, budget 
justification, and idea pitching to the FIRST team. The team collected current ideas, developed an estimate for other activities that aided the central effort of building a facility for collaboration, and justified what they believed would be an equitable portion of the CAS budget. These actions took place in early 2015, and by September 2015 the case had been made to the CAS program that AFRC would benefit greatly from this new investment. The FIRST team received approximately $\$ 500,000$, excluding outside funding.

Acquisitions comprised the following four main areas, for a total cost of around $\$ 500,000$ :

(1) Facilities upgrades for a collaboration and innovation environment;

(2) Furniture acquisitions to aid in the application of the collaboration and innovation environment;

(3) Hardware and appliances for the collaboration space and maker's space; and

(4) Training, comprised of site visits, Front End of Innovation (FEI) conference attendance, and Back End of Innovation (BEI) conference attendance.

A high return on investment was expected for the facilities upgrade, paired with individual "change agent" efforts, because the plan was to find early adopters while coordinating events of no cost but time. The FIRST team conducted a "brown bag" ("bring your own lunch") informational luncheon to gauge the innovative "pulse" of AFRC. The luncheon was largely successful, but for unexpected reasons, which are discussed below.

\section{Current State}

In order to understand exactly what needed to be accomplished, it was important to understand why previous efforts had failed. One such effort included gathering modern and modular furniture into a room at a corner of AFRC. The location and the items were chosen based on a limited budget and available space. This space was far removed from the sight of the majority of the population and not easily accessible, nor was the space advertised or showcased as a common space. The result was minimal use of the space and an ineffectiveness in changing culture. This space, however, was ahead of its time for NASA, was well designed, and could have been successful had it received better support.

An AFRC bike share program also had previously failed, because of improper planning, lack of cohesive implementation, and lack of branding. One of the problems was that the bicycles were not unique in appearance individuals tended not to distinguish bike share bicycles from personal bicycles. Over time, individuals began claiming a particular bike share bicycle as a personal bicycle, and locking it in place. Some bicycles were abandoned after the first flat tire, or worse, ridden with flat tires until the wheels were broken beyond repair. Flats due to punctureweed
(Tribulis terrestris) (also known as goathead thorn) are inevitable in the AFRC area for standard bicycle tires and require a designated maintenance crew to counteract. Past failures can create skepticism and a hesitation to support newer but similar ideas, and need to be addressed when starting programs like this one.

\section{Existing Positive Culture}

During the first brown bag luncheon innovation event, the authors presented lessons learned from the BEI and FEI conferences, and then held a question and answer (Q\&A) session. Information gained from the conferences and the Q\&A discussion indicated that the authors' assertion that an innovation culture did not exist at NASA was incorrect. NASA does innovate and has programs that inspire and encourage innovation, but, as stated by a still unverifiable source, "culture eats strategy for breakfast." It is still necessary to spread this aspect of culture. The authors believe that connections between the people within an organization are important to an effective distributed innovation culture.

Throughout the brown bag luncheon it was evident that there had been high risk takers and innovators who continuously fought for more innovative strategies in their programs and projects. This was how the "old NASA" put human beings on the moon in such a short period of time. The authors contend that part of what made the "old NASA" exciting and innovative was the connections between people of all work levels and the ability to work quickly and efficiently with each other. Individuals who had been AFRC employees for over 20 years spoke up with stories about programs that came into being just because another employee decided to experiment with some concepts during their "down time" at work, or between operational tests. Some methods of creating an innovative culture, we humbly realized, had existed for years in pockets and were being re-packaged by public speakers in Silicon Valley. Program managers across NASA, and the individuals at this brown bag luncheon, already embraced this culture and way of thinking.

Despite this, culture still needs and can greatly benefit from some level of change. Many individuals experience a lack of connection across AFRC and don't feel an innate ability to innovate. It continues to be difficult at AFRC to retain younger employees from other Southern California employers and other NASA Centers. For example, $75 \%$ of the workforce was over the age of 40 in 2016, and $17 \%$ of the workforce was eligible for retirement. In fact, the situation would only get worse if nothing were done to retain the newer employees; $22 \%$ of the workforce would be eligible for retirement in the next five years (2017-2022). The average age of employees was 49 years old, leaving generational gaps difficult to bridge and cynicism about different generations pervasive [Ref. 3]. There is a problem with the culture in it not being "how things used to be," but it is important to recognize existing pockets of positive culture and find a way to expand that culture beyond those pockets. The FIRST team believes that an effective way to expand this culture and further foster a culture of connection across AFRC is to create 
an innovation/collaboration space that can incubate and spread this culture in a clear and distinct way.

\section{DESIGN: INNOVATION/COLlaborATION ROOM}

Core elements of the vision for the innovation/collaboration space remained the guiding principle throughout design and decision-making, and focused the FIRST team on changing culture and fostering innovation. Major elements included:

(1) A space for people across the Center;

(2) A welcoming and open space;

(3) A distinct atmosphere;

(4) Tools to foster collaboration/innovation; and

(5) Focus on people and connections.

All aspects of the final design are related to one or more elements of the vision.

Once the vision for the space was formed, research was conducted to better understand how to design the room and what specific elements could be incorporated. Research included members of the team attending the FEI conference and visiting various companies, including Palantir, Google, and Ideo in San Francisco, California, and the Ames Research Center. Throughout all of these visits the FIRST team kept in mind that the work is done differently by the United States Government than by private companies, and that implementing every practice is not feasible. Talking with company representatives helped the FIRST team gain understanding in those elements they found important. The research that was gathered both about events and room design heavily influenced the ultimate implementation.

The location was already determined for the innovation space, so the FIRST team worked with AFRC facilities personnel to modify the space to meet the vision. An advantage was that the room adjacent (labeled "ALC" in Figure 1) to the designated space was used to conduct training. A portion of the existing research library would be moving from its current location to the innovation space, so the old research library location could be used as the training room. The proximity of the new training room location to the human resources (HR) department was also advantageous. The research library needed to be moved to the innovation space and the training room moved to the old research library space with minimum impact on services provided, which posed its own challenges. By coordinating with facilities contractors and the research library staff, the research library materials were moved and appropriate requirements gathered from HR for implementation in the old library space. Communication was maintained with HR throughout the process to ensure their requirements were met.
The design and construction of the innovation space room was kick-started by the FIRST team having multiple sessions with the master planner and architect of AFRC, Gemma Flores. Information from her experience was obtained, and FIRST team research results were shared. Brainstorming and working through plans in person with those who would actively be executing the plans enabled the FIRST team to iterate ideas, produce a notional idea, get estimates, prioritize design elements, and bring design and construction experience into initial stages.

\section{Structural Design}

The re-design of the existing room included modifications to the walls, floor, and ceiling, and the addition of permanent counters and windows. The space was modified heavily to open it up more and create a kitchenette with microwave ovens, a common refrigerator, and a sink. The walls labeled accordingly in Figure 1 were removed as part of the construction. Removing the wall between the old training room and the new innovation space allowed a more fluid and connected space. These two spaces still feel separated insofar as their function while setting a tone of openness between them. A requirement existed for a Library Technician to be housed near the research library circulation collection, so one of the offices, labeled "Library Technician" in Figure 2, was kept intact, while the other office was removed to make room for the kitchenette. This configuration keeps most of the noise from the kitchenette contained. The temporary partitions labeled in Figure 1 as "removed partitions" were initially planned to be converted to glass-walled suites ("hotel suites") to allow more private collaboration and focused work; however, unexpected costs demanded a reprioritization of design desires, and the hotel suites were removed from the design.

The initial design for the floor called for an industrial feel with clean, finished concrete. After the worn carpet was removed, however, it was determined that the cost of leveling and finishing the concrete would be significantly greater than purchasing new carpet. Although the concrete floor was a strong element of the design, more critical elements of the design took precedence. The new carpet is a pattern of 1- by 1-meter tiles that allow easy replacement in the case of spills, tears, or other damage, and is distinctly different from any carpet used elsewhere at AFRC.

The ceiling of the innovation space was initially $8.5 \mathrm{ft}$ high. Part of the new design requested the ceiling to be raised $1 \mathrm{ft}$. Although this $1-\mathrm{ft}$ change might not seem significant, it increases the volume of the room by a perceptible $12 \%$. According to Meyers-Levy and Zhu [Ref. 4], a change in ceiling height can relate to different, more abstract forms of thinking. The study contends that these forms of thinking might result from a salient change in ceiling height; even so, the ceiling in the new innovation space room is different from that in the other parts of the building, and could help induce the desired atmosphere. Raising the ceiling was a major cost due to the additional task of adjusting fire sprinkler heights 
and rerouting conduit, but the FIRST team felt it was a critical part of the design.

Through the initial stages of design brainstorming, the FIRST team members thought about typical areas where natural conversations happen and atmospheres in which people enjoy collaborating. Bars and coffee shops are two locations that demonstrate these characteristics. Thus, bar-height counters were designed throughout the innovation space. These counters are located along a wall and around a pillar; bar-height chairs are provided so people can sit at the counters to work. This design allows for focused work when necessary in an open space and atmosphere by enabling users to face a wall or a window, but also is conducive to collaboration between a few people who are sitting next to each other.

From the perspective of the FIRST team, the most important element of the design is the large windows that replaced a large portion of the solid walls. These windows "open up" the room, provide a welcoming atmosphere, and further contribute to the coffee-shop feel. As budget changes were made, the windows were considered a critical part of the innovation space and remained the top priority. Research into the architecture of other companies showed that windows that bring in natural light are an important element of any creative/collaborative space; however, the location for the innovation space being predetermined and an interior room, there was no easy access to natural light. The windows were thus placed facing the building hallways, to provide an openness to the room and to bring in more people. Humans are disinclined to enter a room into which they cannot see, even if the room is labeled appropriately, unless they have already been there, have a reason to be there, or are led there by someone else. But if a person can see the entire interior of the room, the type of work that is happening in it, and from this view sense the atmosphere of the room, they are much more inclined to enter and explore. This organic form of exploration can then lead to more interactions and more use of the room for its intended purpose of connecting people. Finally, the windows also provide an opportunity for people inside the room to "people-watch" and work in in a coffee-shop-like atmosphere. People walking past can see who's inside the room and interact through the windows, or come in and talk to those inside the innovation space. This form of connection between people is a valuable part of the design, and leads to collaboration and innovation.

Most elements of the room were designed to be noticeably different from the rest of the Center. From the paint to the carpet to the color of the ceiling tile, the innovation space room was designed to offer a clearly distinct atmosphere.

\section{Kitchenette}

Part of the Center Director's vision was to make a space that was a combined break room and collaboration space. In keeping with that vision, and realizing that people tend to congregate naturally around food and water, the team sought to combine elements of a break room into the innovation space. The layout of the kitchenette is shown in Figure 2. The counters in the kitchenette enable individuals to come and eat, and warm up their food in the microwave ovens, or groups to provide catered meals for specific events held in the innovation space. The kitchenette is located in such a way as to separate it from the rest of the room and contain most sounds. Coffee and espresso machines were installed to encourage people to come and use the space; supplies are provided by donation. A refrigerator is also provided. When projects or groups hold events in the innovation space or elsewhere, comestibles can be donated and stored in the refrigerator or on the counter to encourage a community feel. The kitchenette is often the initial reason that an individual enters the innovation space room; impromptu conversations and connections can then ensue.

\section{Furniture}

The modular furniture in the innovation space was purchased to complement the room and create the innovative and collaborative atmosphere that is being fostered. Implementation of other, smaller, modern spaces at AFRC gave experience and knowledge about what kind of furniture worked well for collaboration and what people enjoyed using. The four main components of collaboration furniture purchased for the innovation space room included mobile whiteboards, comfortable chairs with built-in tables, and foldable and stackable chairs and tables. All of these items can be moved around the room and arranged in various configurations to facilitate conversation and meetings. The modularity of the furniture is utilized extensively in the innovation space to fit the purpose at hand. In addition, two permanent, large, dry-erase boards were placed in the room ("whiteboard" in Figure 2) so that groups can gather around them and converse using larger drawing surfaces. The foldable and stackable chairs and tables provide a way to create smaller private work spaces or larger surfaces with more seating without crowding the room. All of the furniture described can be seen in Figures 3 and 4. Finally, in keeping with the coffee-shop feel and the desire to make this space distinctly different from any other space at the Center, industrial rustic barstools were purchased for all of the barheight counters. An industrial rustic table supported by plumbing pipe helps break up the overall modern style of the room. The FIRST team felt that a purely modern room would induce a predominantly technical and sterile feel that the rustic elements could help dissipate. As such, the pipesupported table and some of the rustic barstools were placed in front of the full-length window as a clear representation of the room. The table itself has generated personnel traffic as people come inside to examine it. The FIRST team believes that any traffic into the innovation space room can start to infuse the desired culture change that is hoped for at the Center. Although the furniture elements themselves do not do anything, they can at the very least show that change is possible and desired. These elements can also initiate conversation and connections between people, which is at the core of the vision and the culture that it is hoped will be realized. 


\section{Décor}

As the FIRST team was considering how to populate the innovation space room, the main driving force was to decorate differently from the rest of AFRC - to foster a different atmosphere. The main elements used were non-aerospace decor, historical artifacts as art, and pictures of people for a collage wall. The non-aerospace decor was specifically placed to encourage a non-technical atmosphere. Although there are references to aerospace and to NASA discoveries and work, all are in some form of creative art, including coffee-themed framed posters, posters of our universe created by the Jet Propulsion Laboratory (Pasadena, California) (posters at https://www.jpl.nasa.gov/visions-ofthe-future/), and framed string craft of airplanes and rockets. By interfacing with the AFRC public affairs office, stores of artifacts were examined to see which could be used to spark conversation or serve as interesting art pieces. Examples include a pitot probe mounted on the wall, a carbon-fiber wing rib, an old punch-card machine, old building signs, and spare window panes from a B-52 airplane (The Boeing Company, Chicago, Illinois) that was used for NASA research. These items were placed around the innovation space without plaques or any indication as to what they are in the hopes that the "mystery" artifacts as art would pique curiosity and result in questions and conversations. Since the innovation space has opened, multiple examples of these conversations have been observed. Finally, a collage wall dedicated to the people who work at NASA was created. Most photographs taken at AFRC are of research work, so the FIRST team members looked through archived photographs to find photographs of individuals interacting with each other or expressing their individuality in some way. The photographs include people from all AFRC organizations in order to further dispel any notion that the innovation space is solely for technical employees to collaborate in and use. Although technical collaboration and innovation is a part of the vision of the room, the deeper focus is on connecting people from across the Center and starting and maintaining conversations and relationships. The collage wall is shown in Figure 5.

A large touch-screen television was also purchased for the innovation space room to serve as a multi-purpose device; the television is mounted in the center of the collage wall (Figure 5). The room contains a sophisticated piece of collaboration equipment that can interface with other NASA aeronautics Centers; the television is used to schedule the collaboration system. By using the television method of scheduling, people are encouraged to get out of their cubicles and go into a common space to schedule use of the collaboration technology. The television also has other accessible applications that allow the user to play musical instruments, learn about the universe, and have access to a variety of free Khan Academy courses. More applications for the television are planned to be obtained in the future. It is hoped that the touch-screen television will serve as a welcome to the innovation space and further promote the collaborative atmosphere of the room.

\section{Unexpected Costs}

After construction began, a few surprises caused the FIRST team to re-evaluate the budget and prioritize elements. Two of the more time- or resource-intensive changes were the extra engineering required to place windows in the walls and the discovery of asbestos in one of the walls. As the plans for the windows were being finalized it was realized that additional analysis and engineering was needed to ensure that the window would be created so as to support the wall above it. This process took some time because outside engineering support and internal approvals were required, which in turn required providing guidance to the onsite contractors as to how to proceed in the meantime. Discovery of asbestos in the wall required a stoppage of work, an analysis of the situation, and a determination as to how to mitigate the risk. Although it was determined to be safe for work to proceed as long as the asbestos was undisturbed, the costs associated with the analysis plus the delay in time caused the FIRST team to prioritize elements of the design. These costs, along with other minor cost changes, resulted in the decision in favor of carpet-tile flooring over concrete, the decision to install only two of the three designed windows, and the decision not to build the hotel suites. Nonetheless, the need to open up the space more, raise the ceiling, and have the main windows as part of the room was maintained. The team considered these elements crucial to the success of the room, and so did what was necessary to retain them.

\section{Implementation Philosophy}

Through the design and construction of the innovation space room, the FIRST team formulated a philosophy on how the vision would be implemented in the room. The room is a common space for anyone across the Center to use, and one in which everyone is welcome to step away from their desk to either have discussions or just work in a different atmosphere. The following rules were established:

(1) The room remains open and unlocked at all times,

(2) The room cannot be expected to be a quiet environment,

(3) Coffee supplies will be provided as long as donations can keep up with demand,

(4) Everyone takes ownership of the room and cleans up after themselves, and

(5) The room cannot be reserved for specific groups of people.

Although there is an expectation that everyone will take ownership of the room, the contract that provides the cleaning staff for AFRC found it within the scope of the contract to vacuum the carpet and empty the trash in the room.

A part of the philosophy of the room is that eventually it should become obsolete. The room serves as an initial incubation of what culture can be like and what working at 
NASA can look like. From there, this culture and way of approaching work should spread beyond the innovation space room and to the rest of AFRC. When the culture has been properly incubated and is infused into the rest of the Center, the room would by definition be just another room, and not a unique one with the focus of shaping culture.

\section{Design: Bike Share Program}

The vision behind the bicycle sharing (bike share) program at AFRC is to encourage employee interaction across the Center and to promote wellness. The program is also meant to complement the vision of the innovation/collaboration space. The FIRST team believed that if the amount of time and effort needed to travel between buildings at AFRC were reduced, more people would take the opportunity to get out of their local work areas to have face-to-face conversations. Lessons learned from previous attempts at a bike share program helped the team develop a few requirements for the current one:

(1) The bikes shall be low maintenance: A dedicated person is not available to oversee the program, so the bikes need to be low maintenance in order to decrease the amount of volunteer maintenance hours.

(2) Replacement parts shall be acquired: The parts most likely to fail are purchased ahead of time in order to reduce recurring costs.

(3) A maintenance program shall be established.

\section{Bike Selection}

Research was conducted to find the bicycle that would require the least maintenance. The team considered four important characteristics:

(1) Belt drive: Removes the need to lubricate the chain and creates less mess;

(2) Puncture-resistant tires: Fewer flat tires means fewer maintenance hours;

(3) Internal or no gears: Reduces the number of exposed parts that can cause problems; and

(4) Back-pedal brake: Reduces the number of moving parts (no front or rear cable brake system); the complexity of the braking system is reduced, which in turn reduces required maintenance.

The Priority Bicycles (New York, New York) "Continuum" model bicycle was chosen based on the four desired characteristics. ${ }^{1}$ This company touts its bicycles as "The first innovative low maintenance belt drive bicycle for the

\footnotetext{
${ }^{1}$ Disclaimer of Endorsement: Neither the U.S. Government nor NASA endorse or recommend any commercial products, processes, or services. Reference to or appearance of any specific commercial products, processes, or services by trade name, trademark, manufacturer, or otherwise, in NASA materials does not constitute or imply its endorsement, recommendation, or
}

recreational rider, designed to make cycling simple" (http://www.prioritybicycles.com). These bicycles met all of the desires of the team, and are also made of aluminum, resulting in a lighter and rust-free bike. This combination of features makes for a very low-maintenance bicycle. The number of times that the volunteers have needed to maintain the bikes is low, and so is the price required for upkeep.

\section{Bike Stations}

As part of the bike share program, key locations around AFRC were selected for bike stations. The idea is for the bikes to be used mainly between the bike stations, so that users know where to go to find a bike. Occasional and short trips to locations without a bike station are allowed as needed, as long as the bike is eventually returned to a station. The stations are marked clearly with signs that share the rules of the program, as seen in Figure 6.

\section{Feedback System}

During the conceptual development of the method of collecting feedback for the bike share program, three elements were deemed necessary:

(1) How often the bikes are used,

(2) How many different users there are, and

(3) Whether there is a need for more bikes.

Standard ways to acquire these metrics are to use a sign-in sheet on which people write their name and perhaps some notes, by requiring a user to report to a common location that a bike was used, or by sending out an occasional survey to the general population. Although the survey provides higher-resolution data with more information on the demographics of people using the bikes, the drawback is the amount of time it demands of the user. In order to best capture metrics, the feedback system was designed to be obvious to a bike user while having minimal impact on that user. One option to reduce impact is to use tokens that represent the three metrics. The design of the token must convey the intent clearly, encourage the user to partake in the feedback, secure the tokens from the wind, and be of minimal cost. The idea was chosen to use the tokens, giving each type of token a different color and face to clearly indicate its meaning. The designs chosen for the three different tokens are represented in Figure 7.

Signage was provided to efficiently convey to the bike user the intent of the feedback system (Figure 8). The user removes the relevant token and places it into a secured box ("Feedback Box" in Figure 8) attached to the signage.

favoring by the U.S. Government or NASA. The views and opinions of authors expressed in this paper do not necessarily state or reflect those of the U.S. Government or NASA, and they may not be used for advertising or product endorsement purposes. 
The easiest way to secure the tokens to the bike share signage is by using a simple hook; however, the high winds common to the AFRC area gave concern that the tokens would separate from the hook and thus become a FOD (foreign object debris) hazard to AFRC flight operations. Adding an additional bend in the hook did not prevent wind dispersal of the tokens. The next option was to secure the tokens using a carabiner-like locking mechanism. This method would require additional effort on the part of the bike user, and was to be avoided if possible. The final iteration of the idea of how to secure the tokens was to use flexible metal that would retain its shape after deformation. The final version of the token retention device is shown in the inset in Figure 8. Bike users can easily pull a token off the flexible metal retention device, and place the token into the feedback box, also with little effort. Unused tokens remain secure on the retention device in windy conditions, meeting safety and flight operations requirements.

All elements of the feedback system were designed to assign the burden of collecting data to the owner of the program, not the users. Data collection does need to be balanced, based on the time available to the owner versus the user, but minimizing the burden on the user could mean more feedback and a more accurate data set.

\section{Maintenance}

One of the biggest concerns of the bike share program was the sustained maintenance of the bicycles. As discussed above, the first step in mitigating this concern was to purchase low-maintenance bicycles. There will be maintenance needs, however, and as such, the FIRST team created a volunteer force of bicycle maintainers and communications channels to report maintenance problems. The volunteer force initially consisted of the creators of the bike share program; however, by asking around and gauging interest, the team was able to recruit a few individuals who valued the bike share program and volunteered their own time for fixing the bicycles as necessary. A voicemail line was also set up for people to call to leave reports of problems with the bicycles. The voicemail line was chosen so as to encourage people to call the number. There are no voice prompts and only a minimal message, reducing the amount of time that the user is on the telephone reporting the problem. To create ownership of the voluntary force and get people excited about being part of it, a brand was created around the group. The group was given the name "repair droids," which is reflected in some of the signage and in the voicemail message. In the future, the team would like to expand the branding to include self-funded shirts that can identify repair droids. This approach could expand awareness of the existence of both the repair droid group and the bike share program. As well, the sense of community that is developed will encourage more people to join and volunteer; the more people who volunteer, the faster the bicycles can be returned to service. The team also has a vision to create informal classes outside of work hours in which individuals from across AFRC can learn to work on bicycles while fixing the actual bike share fleet.
The most frequent problem encountered with maintenance is the need to fix tire punctures. Although the tires are puncture-resistant, some desert foliage is able to easily pierce the tire and puncture the tube. The team is analyzing the viability of self-repairing products that go into the tube. Some experience indicates that the best time to put the self-repair product into the tube is after the first puncture. Tubes have become clogged over time with these products and have required replacement; however, once the puncture is present, the self-repair product can only help the situation (the alternative is, in any case, to replace the tube).

\section{RESUlTS: INNOVATION/COLLABORATION SPACE}

\section{Lessons Learned}

(1) Interface with people who have a similar vision. Engaging with people who have a similar core vision can help with maturing an idea and getting it accomplished. In the case of the innovation/collaboration space, the Center Director's vision matched well with that of the FIRST team, and the project champion also understood the core of what the team was trying to do. The architect who was helping the team design and implement the room also could share in the vision for the room. Having the support of decision-makers and those who could communicate with the necessary parties to move things forward simplified the process. Diversity of thought is important; the authors are not suggesting surrounding yourself with those who think like you. Rather, find people who have the ability to move things forward and who also share in the same core vision.

(2) Have face to face discussions. Several times during the design and construction phases of the innovation/collaboration space project a face-to-face discussion helped the project move forward at a critical point. One example is a misunderstanding between contractors and procurement personnel that brought construction to a halt. One face-to-face meeting with all parties involved was able to start the conversation toward getting what was needed to move forward. Electronic mail and telephone conversations can be so asynchronous that critical decisions can take days instead of minutes or hours to be made. These modes of communication also present the risk of misunderstandings and incorrect conclusions.

(3) Iterate the design. It is beneficial to quickly come to some initial design ideas and then iterate them. When time and budgets are tight it is important to take an idea and go with it. The ability to modify ideas based on research or input results in a more tailored and successful end product. Even after the completion of the innovation/collaboration space, the team realizes that the use of the space is slightly different than what we expected. As an example, the team members expected that the sophisticated piece of collaboration 
equipment system in the room would need to be walled off with glass barriers for privacy. Once the room was open, however, and its use observed, team members realized that the collaboration equipment system was often used during large informal gatherings for collaboration, discussion, and knowledge transfer. Permanent walls in that area would have resulted in the loss of a very valuable use and feel of the room. When the topic of these privacy walls came up again, team members came up with the concept of a movable glass wall, which would allow privacy while still keeping the open feel of the room. Continuous and quick iterations allow quick implementation and better solutions, especially when tight budget deadlines exist.

(4) Identify and stick to fundamentals. Once the core vision of a space has been realized, the elements that most contribute to that vision will need to be determined. At that point, everything else needs to fit into that mold whenever possible. The windows, raised ceiling, and counters provided a very specific atmosphere to the room that the team felt was crucial to inducing the desired cultural change at AFRC. As a result, other elements had to be forgone as costs went up. In the end, the fundamental elements have contributed the most toward the overall atmosphere of the room.

(5) Choose wisely whether or not to have "hotel suites." Many collaboration spaces have "hotel suites" (small, private offices, often glass-walled) into which small groups can go and collaborate without much distraction. This capability is absolutely an important element of a collaboration space. In the innovation/collaboration space, however, it turned out that not having the suites proved beneficial. Although the suites would have provided great value, of greater value is having the larger open space where people can congregate and not feel confined to tight quarters. The FIRST team believes that the open layout creates a more valuable atmosphere for cultural change than would the suites, considering the size of the space. Floor space should be considered when deciding for or against putting in these suites.

(6) Prepare for the unknown. Although it is not possible to know what exactly can go wrong, be willing to iterate designs in order to overcome obstacles. One way to prepare for this is to know the elements of a room that will be fundamental to the vision. Knowing these fundamentals will help steer the design to accomplish the vision while navigating the unexpected.

(7) Have electrical outlets in the floor. The innovation/collaboration space room has electrical outlets intentionally placed around the room for people to use to plug in their laptop computers, but given the size of the room and the modularity of the furniture, floor outlets would have provided value. Floor outlets can be costly if the floor is concrete; cost must be considered along with other design elements.

(8) Consider colored carpeting. The

innovation/collaboration space was designed for predominantly grays and whites, with some color in the furniture. There is value in purchasing carpet tiles or patterns that incorporate some color. Color brightens a room and can make it feel more informal. The color choices that were made for the furniture and countertops in the innovation space do provide a casual feel, but could be complemented well with carpeting having a little color.

(9) Good ceiling height. Although the authors did not perform research about the impact of ceiling height during the design phase, the ceiling height was raised to dispel the "feeling of a dungeon" and to make the space feel more open. Research was later found that might indicate that the increase in ceiling height could promote more abstract thinking. Research does seem to indicate that a salient increase in ceiling height can create more abstract and relational thinking [Ref. 4].

(10) Have an overseer. The designed space was meant to be a public space where everyone can come and enjoy the atmosphere and accomplish their work; however, to effectively induce cultural change, the room by itself cannot do much. Having an overseer or manager of the space not only can keep the space clean and fresh, but can enable the room to become a hub of cultural activity. For example, the authors have a vision to hold events in the room that will bring people together from across AFRC and foster conversations. These events require thought and good planning and will not be as effective without an overseer. Relying on spare-time-work toward organizing and implementing ideas and events will result in inconsistent and haphazard execution. Although it is possible without an overseer, true cultural change benefits greatly from a dedicated person nurturing and fostering the desired culture so that it can organically spread outward.

(11) Build curiosity. During construction, the room was locked so that people could not see its progress. Once the windows were placed, they were covered with opaque sheets so that nothing discernible was visible through the windows. Speculation arose regarding what the room would be, and some people were able to get occasional peeks into the room. Building this curiosity helped increase the anticipation of what the room would be and created more curiosity and traffic once the room was open.

(12) Use music when possible. The room is often fairly quiet. Especially after the initial opening of the room, individuals had the idea that they couldn't speak loudly in the room. To encourage casual conversations between people, it might be of value to play music at a low level in the room. This desire brings up potential 
copyright problems, which would need to be addressed. The current space does not have music due to the lack of a dedicated person to research the music licensing laws and find a way to implement music in the room.

\section{Observational Data}

No quantitative data were acquired in relation to the innovation/collaboration space, but there are some observational data worth noting. Due to the curiosity created and the signage that was placed at the opening of the space, attendance was quite high throughout the day on opening day. As the days went on, foot traffic slowed as more people had seen what the room was all about. Many people showed interest in looking at the photographs of people on the collage wall, and brought others to see photographs they found interesting. Conversations were sparked about the artifacts, and stories were told about the artifacts. The foot traffic of the initial surge was fueled by curiosity; not many people stayed to converse, collaborate, or work. After the initial surge, the use of the room diminished and the room remained empty for the most part except for the occasional individual who came in for coffee or to see the room.

The next observed phase (a few months after the opening) was small waves of foot traffic as people came in and used the space and worked from there, but the room remained empty most of the time. A few months later, the room seemed to be being used in increasing waves.

Approximately eight months after the opening, there are regular gatherings of people discussing projects or ideas. People from across AFRC come to the space, and use it as a common area to talk about work. Although there are still some waves, the number of people coming in has generally increased and it is uncommon to see the room empty. The modular furniture is often used for small group conversations (three or so people) or for spreading multiple media for collaboration between a few people. Individuals also come to the space to eat lunch and socialize. This diverse use of the space by people across the Center was the vision of the space, and is coming to fruition almost one year after it opened.

The vision for a space like this takes time to be realized. It takes time for people to become accustomed to a different way of operating; seeing people use the space gradually brings more people into it.

\section{Results: Bike Share Program}

\section{Lessons Learned}

(1) Make the bicycles clearly identifiable. If a bike share program is thrown together with a variety of different bicycles, participants will have a hard time identifying which bicycles are personal ones and which ones are part of the bike share program. At AFRC, every bike share bicycle is identical, and the bike share program bicycles are unique enough that they are easily distinguished from standard personal bicycles. As well, a license plate was added at the back of each bike share bicycle to identify it as part of the bike share program.

(2) Have a maintenance program in place. Despite every effort to reduce the maintenance required for a bicycle, some maintenance will be required. A pre-established plan for maintenance is necessary to avoid bicycles falling into disrepair and thus not being used. Bicycles that sit broken for some time also risk being claimed as personal bicycles for work use.

(3) Advertise and make the rules known. If the rules are not spread effectively across the organization, people will see the bicycles and make assumptions about how they can be used. Although a seminar was given before the bike share program kick-off, and related

Center-wide electronic mails were distributed, the rules apparently were not clearly communicated. As a result, specific work groups used the bicycles and then stored them near their work areas, instead of returning the bicycles to the bike share stations. When this action was occurring, fewer bicycles were available for the rest of the workforce to use.

(4) Provide baskets or racks. Baskets can be very important for cyclists who want to transport laptop computers or other small equipment back and forth using the bicycles. Although baskets were provided as part of the bike share program, the large openings in the baskets allowed travel mugs and smaller items to fall out. Basket covers were then purchased, and the baskets are now truly effective.

\section{Data}

Data for the bike share program are based on self-reporting. As such, there is a chance of some error in the numbers. As well, the reporting system used tokens that need to be counted and replaced. These tokens were often counted after (often many days after) all of the tokens had all been used (placed in the feedback box). As such, there were many days for which bike use was not quantified. Despite these shortcomings, the FIRST team has gathered general trend data, with the realization that the data are actually more conservative than reality would out. Finally, data collection was stopped after six months due to the time required for the effort and because the data gathered were sufficient with which to move forward.

Figure 9 presents the data collected from two locations from which the bike share tokens were collected consistently and at the same time. Data points that contain data from just one bike share station and not the other were removed due to the skew that would result. The two bike share stations represented are the most-used stations at AFRC. The data show that the bicycles are used consistently and that there is a regular demand for them. 
Due to the challenges faced in collecting the data in a timely manner and the problems inherent to self-reporting, many conclusions cannot be made from these data. There are two conclusions, however, that seem safe to assert:

(1) There is enough value for an AFRC bike share program to be implemented and maintained.

Consistent, repeated use and a desire for bicycles when none are available show that individuals are able to get value out of the program.

(2) As expected, there is an initial surge in new users that tapers off. The data show that the number of new users does not, however, go completely to zero. There seems to be a slow flow of new people trying the bike share program. This number, however, is low enough that it could be caused by misidentification of tokens and thus might not represent the reality.

Table 1 presents the bike share totals six months after the inception of the bike share program.

\section{Table 1. Bike Share Totals Six Months After the Inception of the Bike Share Program}

\begin{tabular}{|l|c|}
\hline Type of Token & $\begin{array}{c}\text { Number of } \\
\text { Tokens }\end{array}$ \\
\hline \hline New User & 169 \\
Repeat User & 633 \\
No Bike & 422 \\
\hline
\end{tabular}

If some reasonable assumptions are made regarding time saved, the potential impact of a bike share program can be easily understood. Most walking travel times between buildings at AFRC average five minutes. Riding a bicycle can usually cut that time by half or more, but a conservative assumption puts time saved at 1 minute each time a bicycle is used. Using the number of "new user" and "repeat user" tokens from above, it can be estimated that AFRC has saved more than 13 hours of employee time over the course of six months. The authors consider this number to be conservative considering the periods of time when users were unable to self-report due to lack of tokens, the number of people who didn't report, the number of bike trips that were not from station to station, and the conservative estimate of actual time saved. If the times during which a bicycle was not available for use are considered, the potential time saved combined with the actual time saved would be at least 20 hours. As well, there are additional, not easily quantifiable, benefits gained when individuals use a bike share bicycle who might not otherwise do so. The bike share program offers individuals the opportunity for more varied conversation as well as a clean, healthy way of connecting with other individuals at AFRC, ultimately creating a positive framework for cultural change.

\section{CONClusion}

The National Aeronautics and Space Administration Armstrong Flight Research Center (AFRC) innovation space and bike share project received positive feedback overall, from AFRC executive leadership to the general AFRC workforce. Deputy Center Director Patrick Stoliker said with regard to the new innovation space, "I'm excited. This is a physical manifestation of a collaborative space. The way it is done is nice and open. I like the furniture. The way it turned out has exceeded my expectations." Based on feedback and the continued utilization by a large diversity of workgroups and employees from across AFRC, the initial goals of creating a collaboration space and the bike share program are seen to be met. It is too soon to discern whether cultural change truly has occurred, but the innovation space and the bicycles continue to be used, and the authors are confident that the space and the bike share program together comprise an effective framework for cultural change. Small changes in ways of interacting with each other and collaborating with others across the Center have been observed. Ways of approaching work are beginning to change. People are working together in common spaces more often, and spontaneous conversations between people who previously would not have naturally interacted are taking place.

To further encourage this collaborative atmosphere, several forward-looking goals have been set. One goal is to engage a core group of people that have a vested interest in the innovation space to help maintain its usability. The capabilities within the innovation space remain relevant by keeping abreast of emerging trends and culture changes. As well, events can be held in the innovation space that encourage participation across AFRC and create a culture of connection and collaboration. Examples of such events include storytelling workshops and opportunities, group work sessions, problem-solving gatherings, shared-interest workshops, and catered or potluck meals. To more easily execute these ideas, a funding source should be established. Additional innovation spaces in other locations within AFRC could be modeled after this initial space and could utilize the lessons already learned. This spreading of a culture of collaboration can be made easier with the addition of similar spaces across AFRC. The final goal of the innovation space and the bike share program is a culture of collaboration that will be evident in all areas of AFRC and that is not unique to only those individuals who use the innovation space or the bicycles.

When attempting cultural change in an organization, it is beneficial to first determine what framework can be established to foster that change. The authors have proposed that an effective way to begin fostering a culture of connection, collaboration, and innovation is to create a framework that encourages conversation and organic collaboration. This framework can be created by using a dedicated space that creates the desired atmosphere and has elements in place that put its users in a frame of mind that is conducive to conversation and to connecting with one another. Additionally, a bike share program can reduce some 
of the barriers of distance that can prevent individuals from getting outside their workspaces to go and engage in face-to-face conversations. These two frameworks together help foster a closely-knit community that is more efficient, effective, and collaborative.

\section{ACKNOWLEDGEMENTS}

The authors thank NASA Armstrong Flight Research Center Director David McBride for his vision for culture change at Armstrong, and Deputy Center Director Patrick Stoliker for being a champion of the innovation space and bike share projects throughout their execution. We also extend deepest gratitude to Gemma Flores, without whose persistent work and support this project would not have become a reality. Also, special thanks go to Isaac Lopez, Marty Waszak, Starr Ginn, and the CAS project, without whom the project would not have had the funding that made it so successful. We are also grateful to all of the other Armstrong personnel who helped in countless ways to make this project a reality.

\section{REFERENCES}

[1] National Economic Council and Office of Technology Policy, "A Strategy for American Innovation," The White House, Washington, D.C., October 2015.

[2] Amendment No. 6 to the NASA Research Announcement (NRA) entitled "Research Opportunities in Aeronautics 2015 (ROA-2015)," NNH15ZEA001N, Released February 11, 2015, https://nspires.nasaprs.com/external/

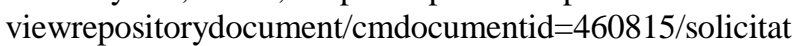
ionId=\%7B56B41277-E146-B2AE-88F5-

427AE81CE622\%7D/viewSolicitationDocument=1/ROA -2015\%20NRA\%20Amendment\%20No.\%206.pdf, accessed August 24, 2017.Aerospace Conference Web site: www.aeroconf.org

[3] Diversity \& Equal Opportunity Council, “Armstrong Flight Research Center Profile,” March 29, 2016.

[4] Meyers-Levy, J., and R. Zhu, "The Influence of Ceiling Height: The Effect of Priming on the Type of Processing That People Use," Journal of Consumer Research, vol. 34, 2007.

\section{ADDitional READING}

(1) Academy of Neuroscience for Architecture: http://www.anfarch.org/

(2) Zeisel, John, and Jacqueline Vischer, "Environment/Behavior/Neuroscience Pre \& Post-Occupancy Evaluation of New Offices for Society of Neuroscience, September 2006, http://www.anfarch.org/wpcontent/uploads/2013/11/SfNExecutiveSummary.pdf, accessed August 24, 2017.

\section{BIOGRAPHIES}

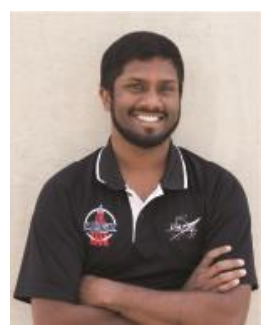

Aamod Samuel is a Flight Systems Design Engineer at the NASA Armstrong Flight Research Center in Edwards, California, holding a BS in aerospace engineering from Purdue University. His past work includes systems and user interface design for the airborne schlieren imaging system and Airvolt test stand. Current work includes design of a command system and user interface for the X-57 SCEPTOR project.

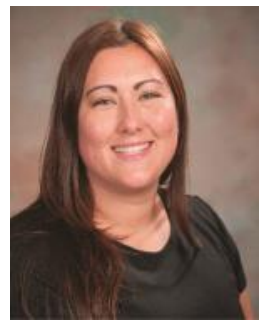

Olivia Carte is a Management Analyst at the NASA Armstrong Flight Research Center in Edwards, California. She has 15 years of experience working for the United States Government in both contractor and civil service roles. She has been with NASA since 2013; prior to that she worked for the United States Air Force. Olivia earned her BS in Business Management from Grantham University in 2012. Olivia currently supports the Mission Information and Test Systems Directorate, which involves managing and executing resources for the Dryden Aeronautical Test Range, Simulation Engineering and Information Technology (IT) Management.

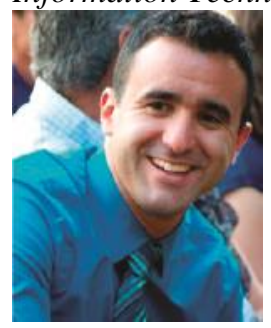

Joel B. Lozano is a Contract Specialist at the Ames Research Center Office of Procurement with almost a decade of experience in contracts, negotiations, and general business for NASA. He holds an MS in aeronautical science from EmbryRiddle Aeronautical University, a bachelor of science and general engineering with an economics major from the United States Air Force Academy, and a private pilot's license.

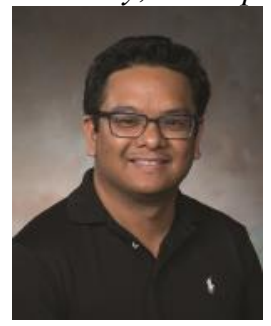

Troy Robillos began his NASA career at the Armstrong Flight Research Center in Edwards, California as a Pathways Intern in 2014. He joined NASA as a full-time employee as an Electronics Engineer in 2016, and is involved in aircraft integration. He received his BS in Computer Science from St. John's University and his MS in Mechanical Engineering from Columbia University. 


\section{FigURES}

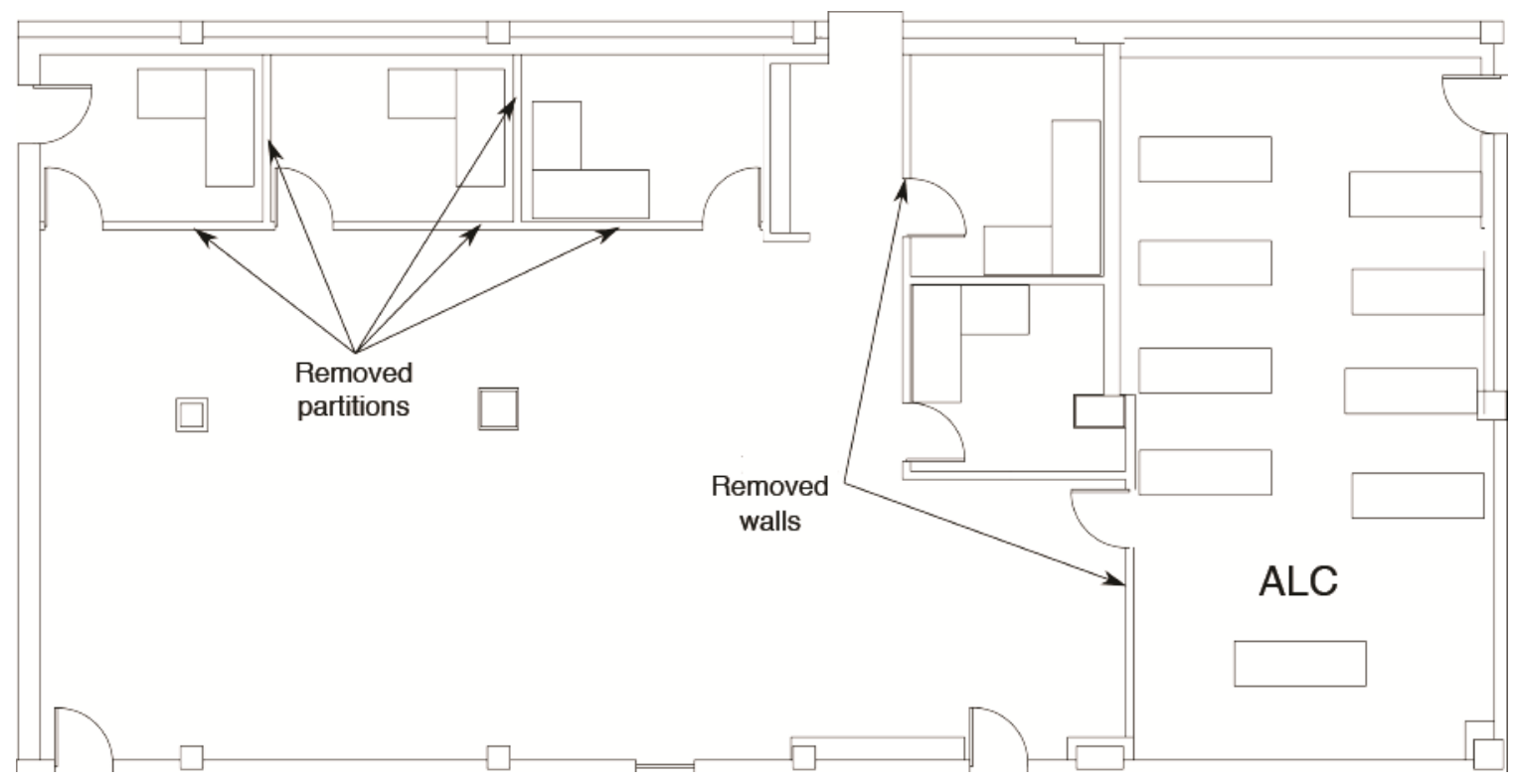

Figure 1. Pre-construction layout of the NASA AFRC innovation/collaboration room.

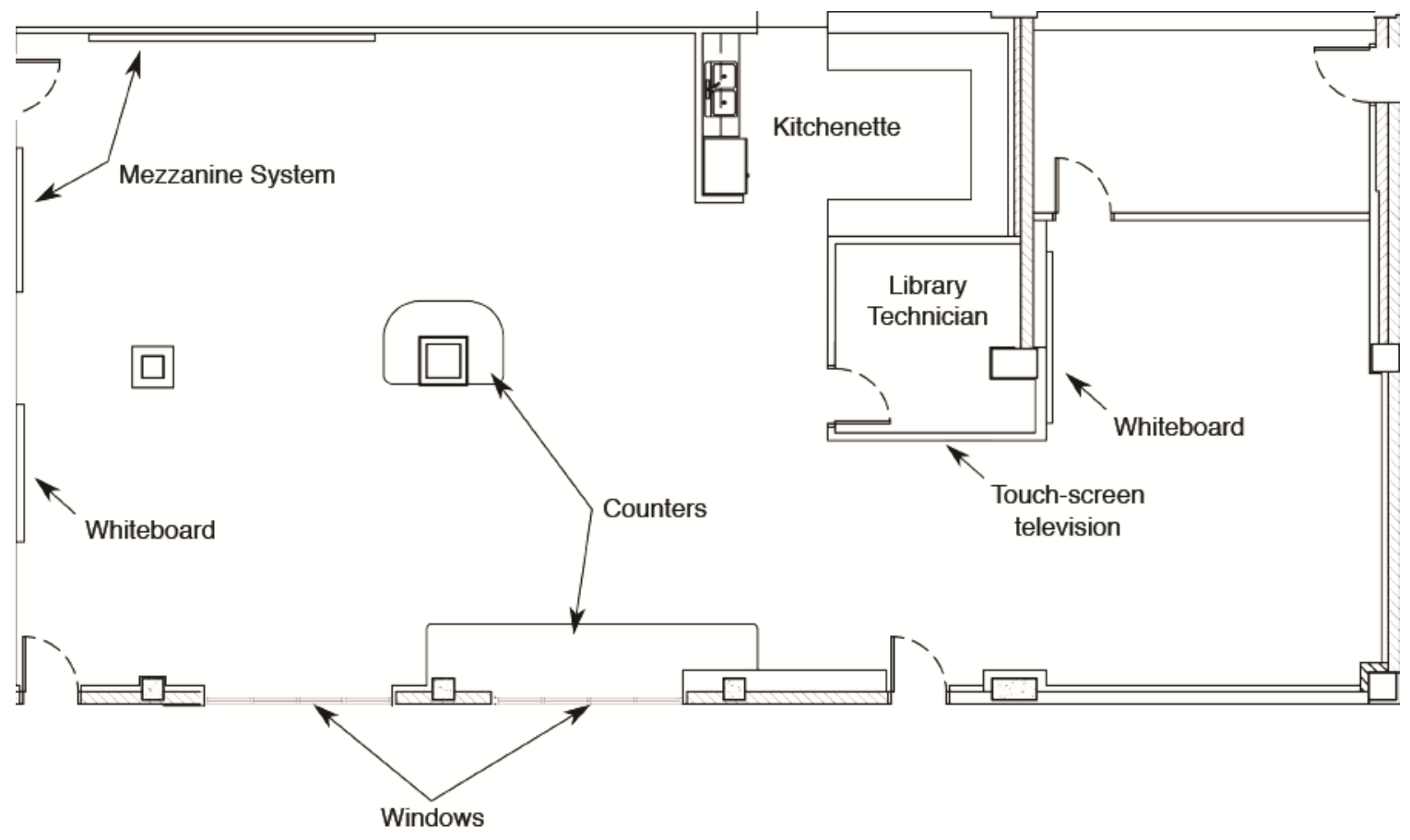

Figure 2. Final layout of the NASA AFRC innovation/collaboration room. 

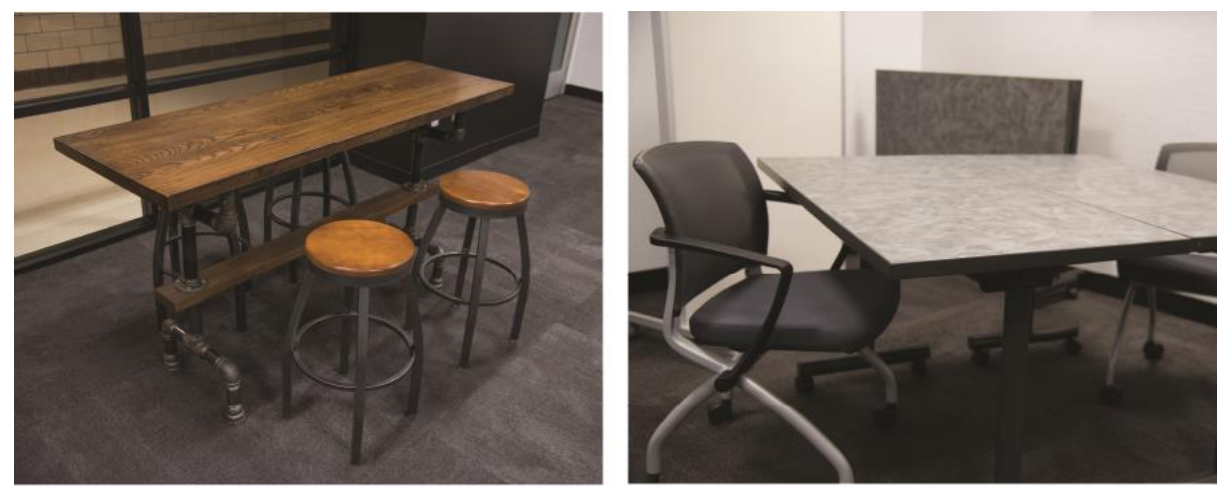

Figure 3. Industrial rustic table with barstools (left); nesting chairs with folding tables and modular whiteboard (right).
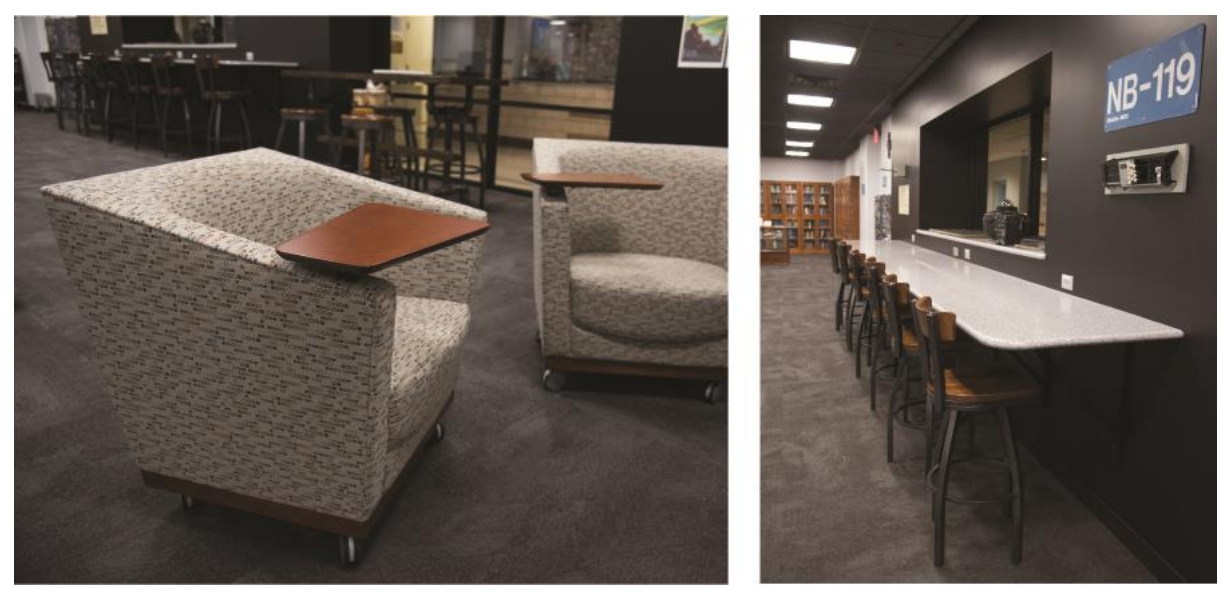

Figure 4. Modular chairs with work tables (left); bar-height counter beneath artifact as art, with industrial rustic bar-height chairs (right).

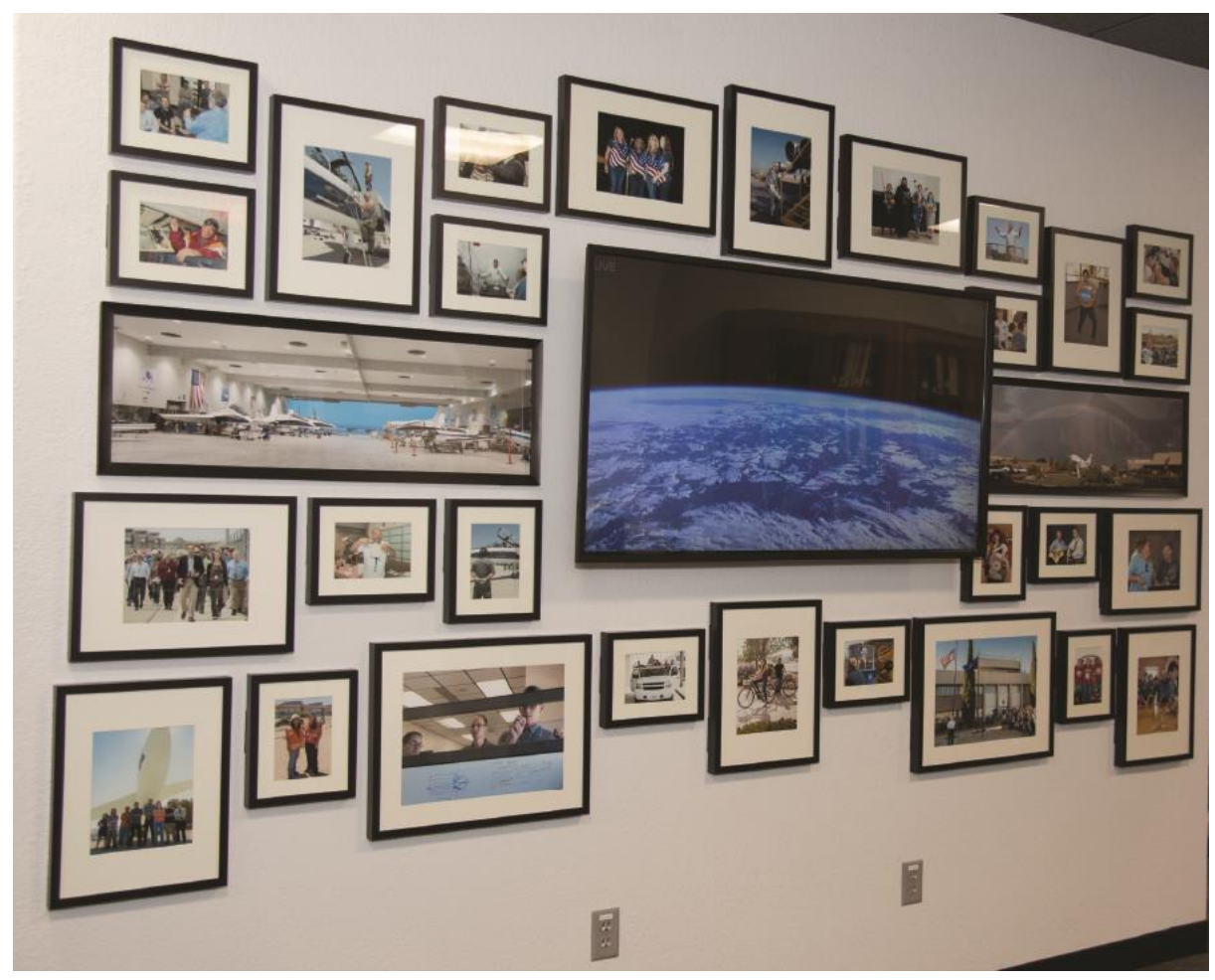

Figure 5. Personnel collage wall with (center) large touch-screen television. 

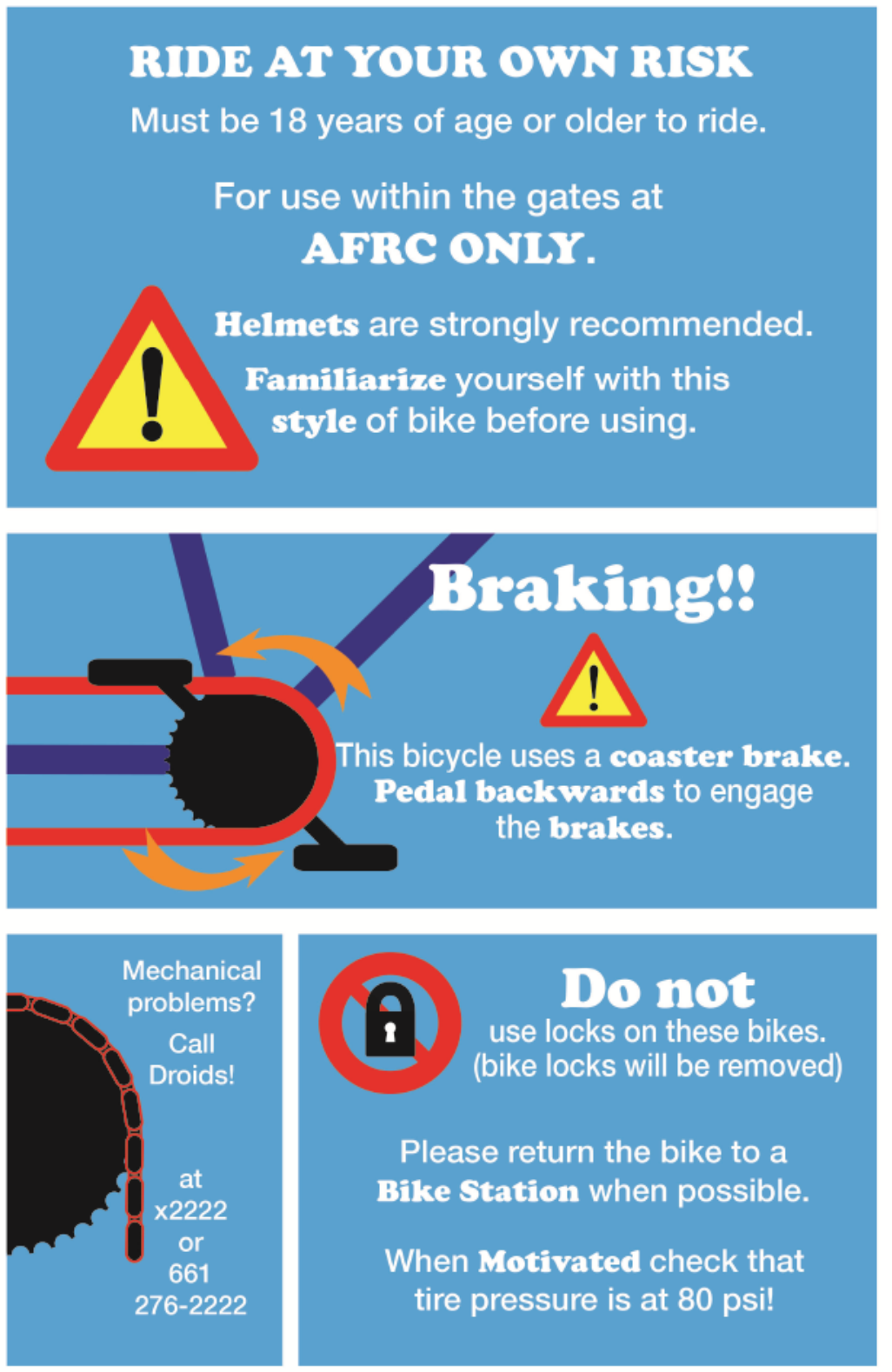

Figure 6. Bike station sign sharing the rules of the bike share program.
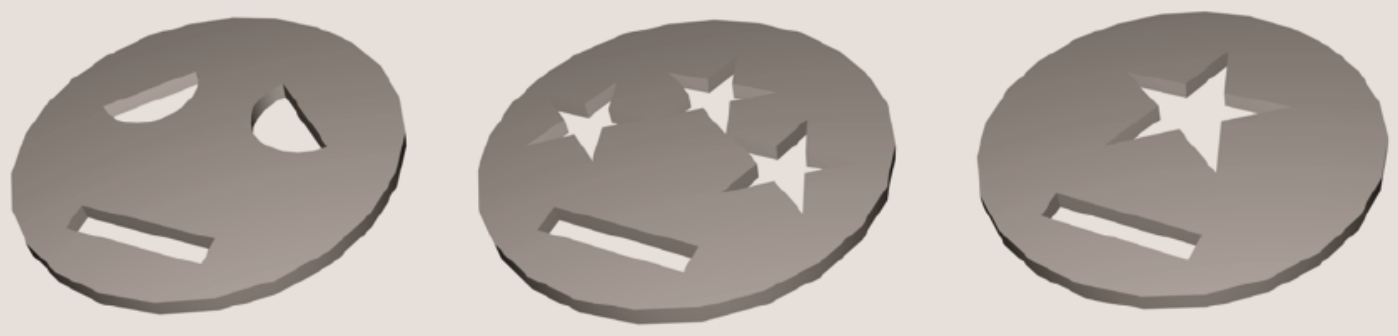

Figure 7. Three-dimensional models of "no bike," "repeat user," and "new user" tokens, respectively. Yellow, blue, and white filament, respectively, is used for 3-d printing the tokens. 


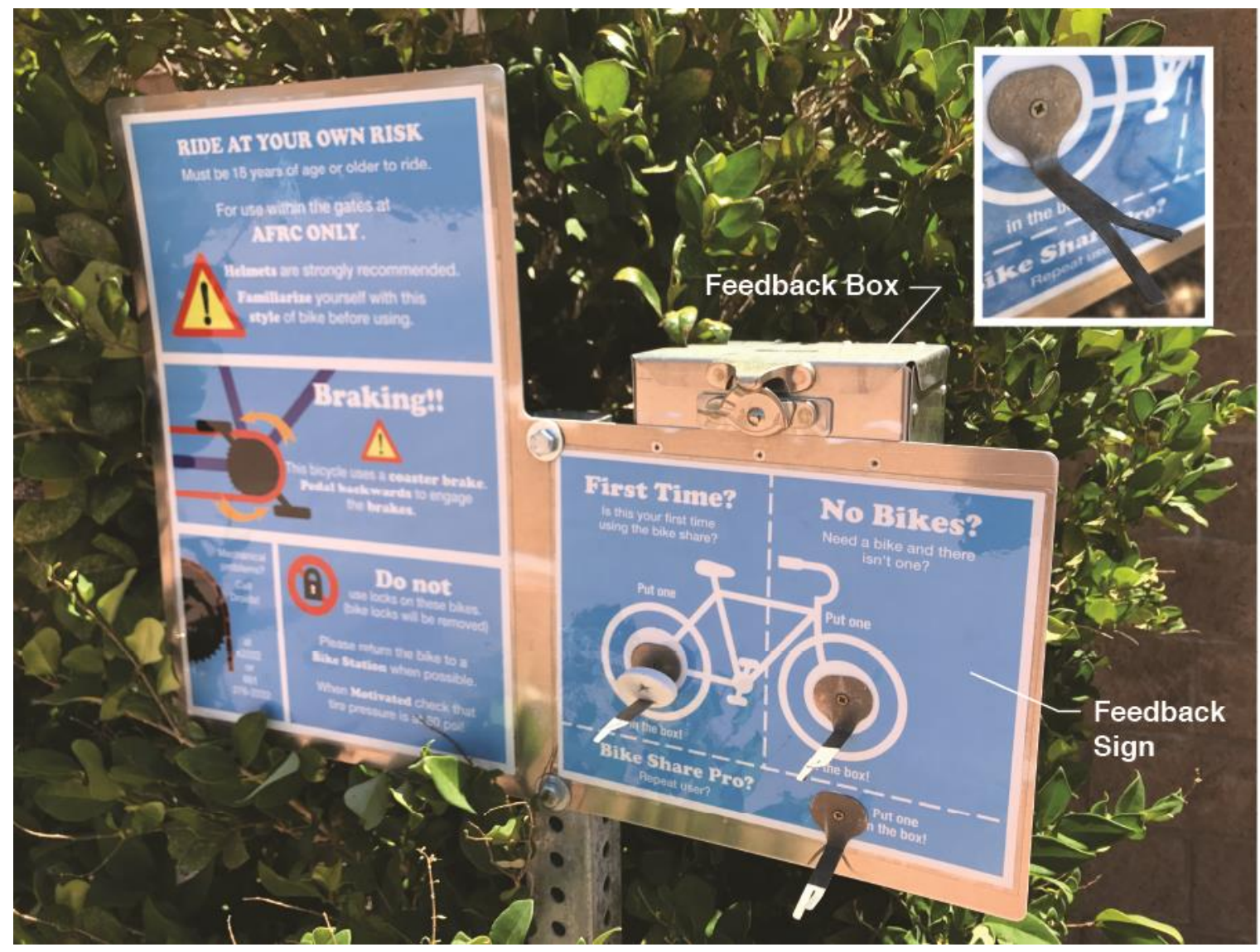

Figure 8. Bike share program feedback sign and box. Inset: Flexible metal token retention.

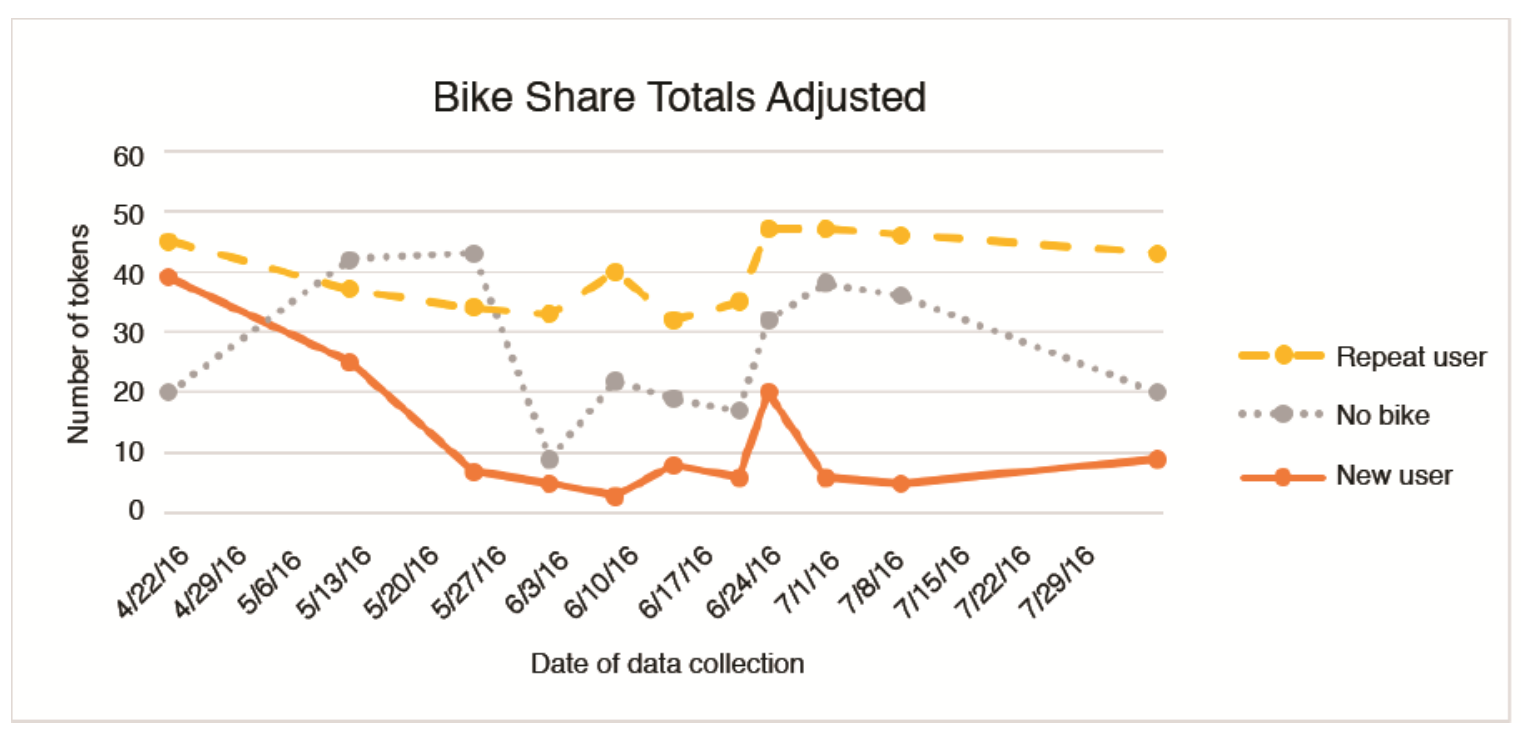

Figure 9. Bike share metrics adjusted for lapses in data. 